\title{
No time left
}

\author{
As the climate crisis continues its deadly course, how much longer will it take for world leaders to act?
}

$\Lambda$ gainst the backdrop of intensifying climate-related disasters that only this year disrupted the lives of thousands of people around the world and were responsible for substantial economic damages, more than 190 world leaders are getting ready to join the table of negotiations at the forthcoming 26th Conference of the Parties (COP26) to the United Nations Framework Convention on Climate Change to be held this year in Glasgow, UK, from 31 October to 12 November.

Climate change is on us. Catastrophic floods in Western Europe in mid-July left more than 200 people dead in Germany and Belgium, with many missing, and other countries such as Luxembourg, the Netherlands and Switzerland also affected. Later in the summer, extraordinary hot temperatures across the Mediterranean Basin triggered unprecedented wildfires with countries such as Greece, Italy, France, Turkey and others losing thousands of hectares of forest and farmland, and reporting casualties and mounting damages. On the other side of the Atlantic, hurricane Ida landed in Louisiana, USA, leaving one million homes without power by the end of August, while wildfires keep spreading across California where thousands of square miles have burnt so far, thousands of homes have been destroyed alongside other buildings, communities have been evacuated and national forests are under threat.

Prominent politicians cried out that more needs to be done about climate change as they can no longer ignore the perils of a warming planet. So what should happen at COP26? Countries should agree on emissions reduction pledges sufficient to limit global warming to $1.5^{\circ} \mathrm{C}$ in order to fulfil the ambitions of the Paris Agreement. Will it happen? Many have cast doubts.

\section{"The youth are right to protest; their future is at stake."}

Climate change protests by the Fridays for Future youth movement took over the streets on 24 September, starting in Asia and then spreading across many European cities and beyond. Greta Thunberg, the young Swedish climate change activist who inspired the movement a few years ago with her solo

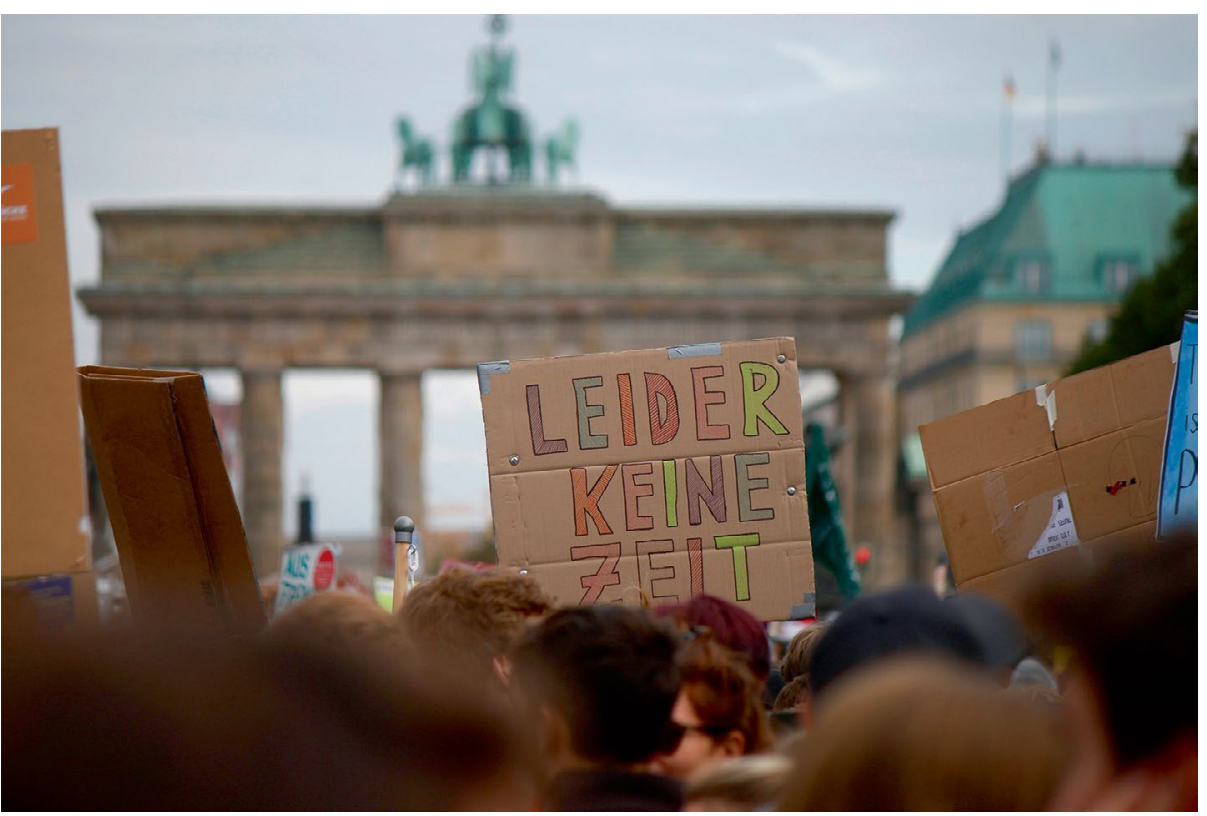

Credit: 360b / Alamy Stock Photo

climate school strike, joined the crowd in Berlin, Germany, two days before the federal elections in the country, voicing the need to both vote and protest in order to trigger change.

Are politicians listening to the youth and those who join them? Maybe.

They definitely can't avoid the subject anymore. The science is solid (see our COP26 collection) and public opinion is increasingly supportive of it. Yet, confidence about any success at COP26 is at best shaky. It seems that some officials have already said that world leaders won't reach agreement on a $45 \%$ emissions reduction target, but they might advance talks on phasing out coal, providing financial support to poor countries and protecting forests. As much as such progress is needed, it is frankly nowhere near enough to address the ongoing climate crisis. Leaders have left the problem unchecked for far too long and we are now running out of time. The youth are right to protest; their future is at stake.

The politics of climate talks are intricate and often reflect geopolitical tensions. Focus is always on the moves of the major emitters. Earlier this year, President Joe Biden announced a new climate target for America: to achieve $50-52 \%$ reduction from the 2005 levels in the economy-wide net greenhouse gas emissions by 2030 . China, the world's biggest emitter of carbon dioxide, pledged to become carbon neutral by 2060 and to push further the adoption of renewable energy to ensure carbon emissions will peak by 2030 . At the time of writing, it is, however, not yet confirmed whether President Xi Jinping will attend the talks in Glasgow. With strained US-China relations, success at COP26 is far from certain.

Whether or not negotiations and dialogue between major players will progress in Glasgow, one thing is certain: pledges alone won't cut it, we need action plans, detailed agendas about the policies and interventions to meet the pledges, and commitment to act. There is no time left for geopolitics, retaliations and myopic self-interest. At the pace the climate crisis is unfolding, too many are set to suffer now, ecosystems are already on the brink of collapse - there is no future sustainable development path if the ambitions of the Paris Agreement are not achieved. The change is now, and politicians must embrace it.

Published online: 11 October 2021 https://doi.org/10.1038/s41893-021-00795-3 